\title{
The Economic Burden of Bipolar Disorder in the United States: A Systematic Literature Review
}

This article was published in the following Dove Press journal:

ClinicoEconomics and Outcomes Research

\author{
Leona Bessonova' \\ Kristine Ogden $\mathbb{D}^{2}$ \\ Michael J Doane' \\ Amy K O'Sullivan' \\ Mauricio Tohen ${ }^{3}$ \\ 'Health Economics and Outcomes \\ Research, Alkermes, Inc., Waltham, MA, \\ USA; ${ }^{2}$ Evidence, Worldwide Clinical \\ Trials, Morrisville, NC, USA; \\ ${ }^{3}$ Department of Psychiatry and \\ Behavioral Sciences, University of New \\ Mexico, Albuquerque, NM, USA
}

Correspondence: Leona Bessonova Health Economics and Outcomes Research, Alkermes, Inc., Waltham, MA, USA

Tel + I-78|-609-6439

Email leona.bessonova@alkermes.com
Abstract: Bipolar disorder (BD) is a mood disorder with subtypes characterized by episodes of mania, hypomania, and/or depression. BD is associated with substantial economic burden, and the bipolar I disorder (BD-I) subtype is associated with high medical costs. This review further evaluated the economic burden of BD and BD-I in the United States (US), describing health-care resource utilization (HCRU) and sources of direct medical and indirect costs Data were obtained from systematic searches of MEDLINE ${ }^{\circledR}$, EMBASE $^{\circledR}$, and National Health Service Economic Evaluation Database. Citations were screened to identify primary research studies (published 2008-2018) on the economic burden of BD/BD-I or its treatment in real-world settings. Reported costs were converted to 2018 US dollars. Of identified abstracts $(\mathrm{N}=4111), 56$ studies were included. The estimated total annual national economic burden of BD/BD-I was more than $\$ 195$ billion, with approximately $25 \%$ attributed to direct medical costs. Individuals with BD/BD-I used health-care services more frequently and had higher direct medical costs than matched individuals without the disease. Drivers of higher direct costs included frequent psychiatric interventions, presence of comorbid medical/ psychiatric conditions, and both suboptimal medication adherence and clinical management. Indirect costs (eg, unemployment, lost work productivity for patients/caregivers) accounted for $72-80 \%$ of the national economic burden of BD/BD-I. Different definitions for study populations and cost categories limited comparisons of economic outcomes. This review builds on existing literature describing the economic burden of $\mathrm{BD}$ and confirmed cost drivers of BD/BD-I. Improved clinical management of BD/BD-I and associated comorbidities, together with better medication adherence, may reduce health-care costs and improve patient outcomes.

Keywords: cost of illness, health care costs, indirect costs, mania, mood disorder, resource utilization

\section{Introduction}

Bipolar disorder (BD) is a severe and complex mental health disorder composed of different subtypes that present variably. The disorder is characterized by shifts in mood (ie, alternating periods of elation, irritability, and depression), energy, and behavior. ${ }^{1,2}$ The lifetime prevalence of $\mathrm{BD}$ is estimated to be $4.4 \%$ in the United States (US), with most cases emerging during adolescence or early adulthood. ${ }^{3}$ BD is a leading cause of disability among young people, ${ }^{2,4}$ and is associated with impairments that negatively impact personal, social, and occupational functioning, and reduce quality of life. 1,2,5-8 $^{\text {1. }}$

Prior reviews of cost of illness studies have found a substantial economic burden associated with BD, and that cost estimates for the disorder vary 
considerably across studies. For example, one analysis estimated the per-person total lifetime costs of BD in the US ranged from $\$ 11,720$ for a single manic episode to $\$ 624,785$ for a disease course marked by nonresponsive/ chronic episodes (1998 US dollars [USD]). ${ }^{9}$ Sources of direct health-care costs for individuals with $\mathrm{BD}$ include medical expenses associated with psychiatric care (both inpatient and outpatient), treatment (pharmacological and non-pharmacological), and emergency room (ER) visits.6,9-11 Persons with BD tend to have higher rates of comorbid medical (eg, metabolic syndrome, hypertension) and psychiatric (eg, substance use disorder, anxiety) conditions, which contribute to higher utilization of general medical services compared to the general population. ${ }^{1,12-}$ ${ }^{15}$ Fewer studies have examined indirect costs (eg, expenditures associated with reduced work productivity, use of caregivers) for those with $\mathrm{BD} ;{ }^{6,10,16}$ yet, their impact is sizable with losses in work productivity previously estimated to represent $20 \%$ to $94 \%$ of the total societal cost of BD. ${ }^{6}$

Bipolar I disorder (BD-I) is a subtype of BD in which individuals experience one or more manic episodes, and accounts for approximately one-quarter of all cases of BD. ${ }^{3,17}$ The disease course for BD-I is typically chronic and is associated with significant functional disability and premature mortality. ${ }^{3,5,18-20}$ Some evidence suggests that BD-I may also be associated with higher direct medical costs compared to other subtypes of $\mathrm{BD}$; however, the reasons for this are poorly understood. ${ }^{6}$ Few studies have elucidated the different drivers that may contribute to greater cost burden for those living with $\mathrm{BD}$, in general, and those with BD-I, specifically.

The objective of this systematic review is to provide an updated report of the economic burden of BD in the US, including a broader spectrum of cost and/or health-care resource use (HCRU) estimates compared with previous reviews. ${ }^{6,10}$ Direct and indirect costs of the disorder are summarized, and drivers of these costs are identified. Where specific data existed for BD-I, these estimates are reported separately from those for BD overall. While BD-I has been associated with higher direct medical costs compared with other BD subtypes, ${ }^{6}$ this review examines broader cost outcomes and drivers of these costs specifically for patients with BD-I.

\section{Materials and Methods}

MEDLINE $^{\circledR}$, MEDLINE $^{\circledR}$ in-process, EMBASE ${ }^{\circledR}$, and National Health Service Economic Evaluation Database
(NHS EED) databases were searched for primary research studies published between 1 January 2008 and 9 July 2018 on the economic burden of BD and BD-I in the US. Search strategies combined terms related to disease and outcomes and were limited to English-language publications only. The full search strategies and search terms are available in the electronic supplementary materials Tables 1 and 2 .

The start year (2008) was selected because it captured a decade of published literature at the time the review was conducted. From 2008 to 2018, several new medications became available for the treatment of $\mathrm{BD} / \mathrm{BD}-\mathrm{I}^{21}$ and multiple international guidelines, including a major North American clinical guideline, were revised. ${ }^{22-28}$ In addition, two federal laws were passed in 2008 and 2010 (Mental Health Parity and Addictions Equity Act [MHPAEA] and Affordable Care Act [ACA], respectively) that substantially changed the insurance landscape and availability of mental health benefits in the US. ${ }^{29}$ Given these collective events, conducting an updated review to understand the contemporary economic burden of BD/BD-I in the US was warranted.

Publications were included if the population of interest was adults with BD (generally or not otherwise specified) or BD-I, and the economic burden of the disorder or its treatment in the US was reported or could be derived. Economic burden was defined broadly; studies that discussed patterns of HCRU without cost estimates and papers that described other economic impacts associated with BD or BD-I (eg, workplace productivity, disability) were included in this review. Inclusion was restricted to studies conducted in a real-world setting (ie, not randomized controlled trials) and studies that included cohorts of at least 100 patients. Studies that focused on bipolar depression only, or on subtypes other than BD-I, were excluded, as were case reports and costeffectiveness analyses and similar economic evaluations of specific medications. Reviews were not included but their bibliographies were screened for relevant studies.

Citations from all database searches were combined; duplicates and excluded publication types (eg, randomized controlled trials, case reports) were flagged electronically and removed. Titles and abstracts for the remaining articles were screened by one reviewer, with independent review by a second reviewer if inclusion/exclusion was unclear. Inclusion was confirmed by review of full-text publications by one reviewer, with queries resolved by discussion with a second reviewer. Data from included studies were extracted into a structured spreadsheet by two reviewers, and disagreements were resolved by consensus. Data specific to BD-I were extracted separately 
wherever possible. The extraction spreadsheet was organized to capture discrete categories of economic outcomes to facilitate descriptive summary of the findings for this review. The methodological characteristics of included cost of illness studies were assessed with the checklist utilized by Kleine-Budde et $a 1,{ }^{10}$ and these results are included in the electronic supplementary materials Tables $\underline{4}$ and $\underline{5}$.

Costs were converted to a common year currency (2018 USD) using the Consumer Price Index (CPI) for
Medical Care ${ }^{30}$ If cost-year was not reported in a study, it was assumed to be the last year of the observation period mentioned in the source publication.

\section{Results}

\section{Literature Search Results}

A total of 4111 abstracts were identified. Following screening, 99 articles were selected for full-text review. After inclusion and exclusion criteria were applied, 56 articles were included in the review. Thirteen studies (23.2\%)

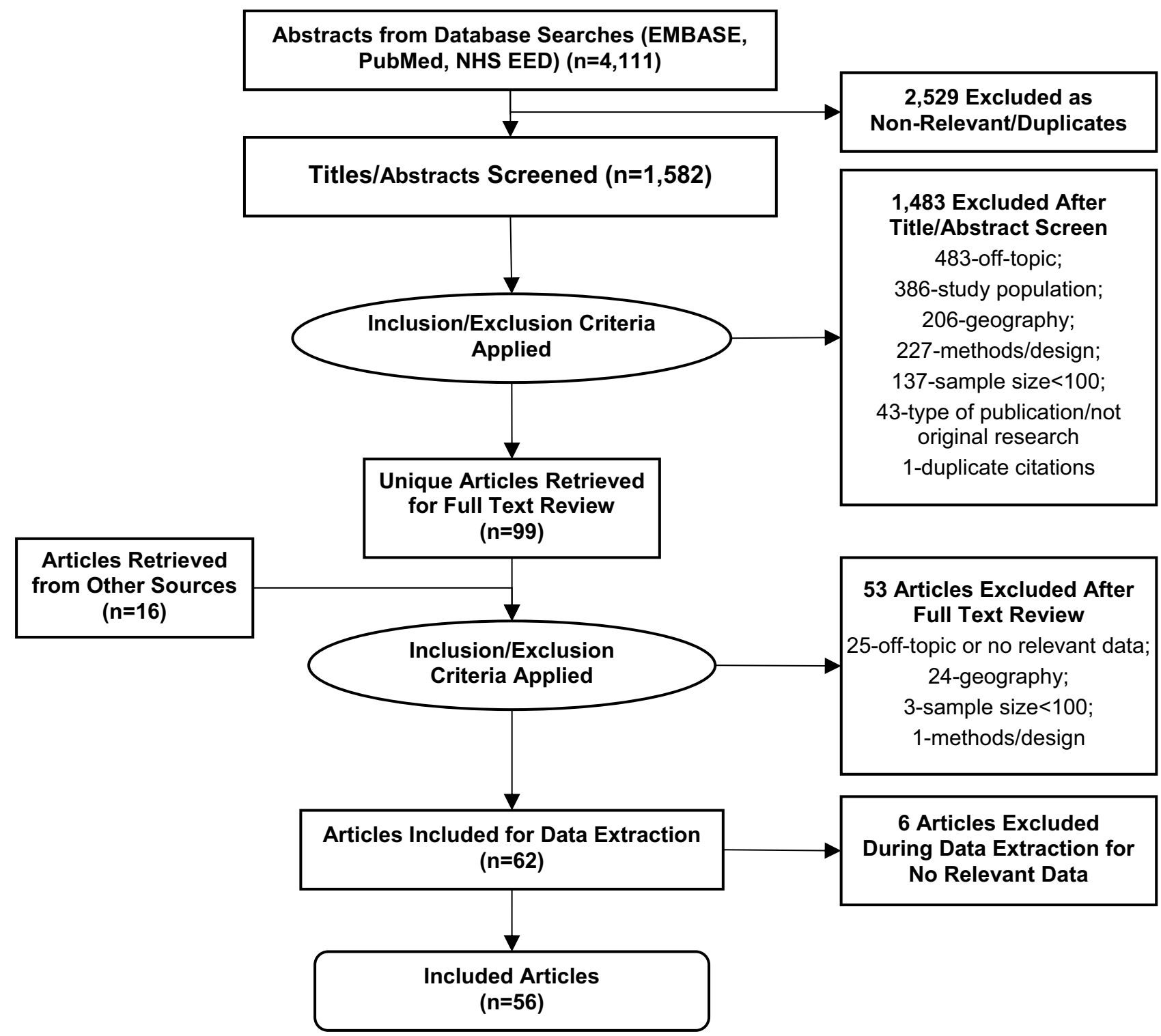

Figure I PRISMA diagram showing the literature search process.

Notes: The 2529 records excluded prior to title/abstract review were eliminated electronically by identifying duplicate citations (eg, records with duplicate identifiers or citation data fields) and publications indexed for excluded types of publications (eg, randomized controlled trials, case reports). The step "articles retrieved from other sources" refers to papers identified from bibliographic review and other known, relevant research papers.

Abbreviations: BOI, burden of illness; NHS EED, National Health Service Economic Evaluation Database; PRISMA, Preferred Reporting Items for Systematic Reviews and Meta-Analyses. 
reported data specific to BD-I, whereas the other 43 studies (76.8\%) reported data on BD (generally or not otherwise specified). The study selection process is shown in Figure 1.

Of the 56 included studies, 30 studies (54\%) reported cost data. The assessment of methodological characteristics of these studies found that most reported their data sources and analysis perspective; however, only 15 studies (50\%) reported the monetary value of all HCRU and 13 studies (23\%) provided separate information about the number of services (eg, health-care) and costs for the cost categories described. Inclusion of sensitivity analyses in these cost studies was uncommon. Of the papers not reporting cost data, 4 studies (7\%) reported on HCRU, and 22 studies (39\%) described other topics associated with economic burden (eg, work productivity, caregiver burden).

The electronic supplementary materials Tables $3-\underline{5}$ provide a list of all studies included in this review and the assessment of methodological characteristics for the cost studies identified.

\section{Total National Economic Burden}

Two studies estimated national costs using prevalence data for BD-I and bipolar II disorder (BD-II) in the US population. Cloutier et al estimated the total annual costs of BD-I in the US at $\$ 219.1$ billion, corresponding to an average of $\$ 88,443$ per person with BD-I per year. This figure included $\$ 50.9$ billion in direct health-care costs (ie, medical and pharmacy); $\$ 9.7$ billion in direct non-healthcare costs (eg, BD-related substance use disorder, criminal justice involvement for those who commit or are victims of crime, prevention/research costs); and $\$ 158.5$ billion in indirect costs (eg, loss of work productivity or premature mortality). The excess costs of BD-I (the difference between costs incurred by individuals with and without BD-I) were reported to be $\$ 129.9$ billion annually, an average of $\$ 52,413$ per person with BD-I per year. Total costs for individuals with BD-I were 2.46 times greater than for controls without BD-I. ${ }^{31}$

A second study estimated the total annual cost burden of BD-I and BD-II at $\$ 194.8$ billion, including direct costs of $\$ 39.6$ billion and indirect costs of $\$ 155.2$ billion. However, the author explicitly acknowledged that these cost estimates were likely to be substantially underestimated, due to certain assumptions on which the analysis was based (eg, prevalence figures that did not include all subtypes of BD; direct and indirect cost estimates sourced from a 20 -year-old cost analysis; the assumption that BD-I and BD-II are equally costly disorders; pharmacy costs that only included lithium). ${ }^{32}$

\section{Direct Health-Care Costs}

Seventeen studies (two for BD-I, 15 for BD) reported on direct all-cause and/or mental health-related costs (Table 1). Some cost estimates for cohorts with BD were higher and spanned a wider range than those reported for patients with BD-I. Several factors may contribute to this variation, including methodological differences between studies, consideration of different cost components (eg, inclusion of emergency room or other costs), and differences in clinical management and available treatments during the periods studied (2004 to 2007 for BD-I and 1998 to 2014 for BD, respectively).

\section{All-Cause Health-Care Costs}

Fourteen studies (two for BD-I, 12 for BD) provided estimates of annual all-cause direct health-care costs (Table 1). Among cohorts with a BD-I diagnosis, annual all-cause direct health-care costs varied from $\$ 11,239$ to $\$ 19,446$ per-person-per-year (PPPY). ${ }^{33,34}$ Estimates of annual all-cause direct costs reported for patients with BD spanned a wider range, from $\$ 11,051$ to $\$ 46,971$ PPPY. ${ }^{35,36}$

A retrospective study of commercial health-care claims reported that PPPY all-cause health-care costs (ie, inpatient, outpatient, prescription medications) for individuals with $\mathrm{BD}$ were about four times higher than for matched individuals with no mental health disorders and no psychotropic medication use $(\$ 19,131[\mathrm{BD}]$ vs $\$ 4706$ [no mental health disorders]). ${ }^{12}$ A separate study reported that individuals in an employer-based health plan diagnosed with BD had higher allcause, mean per-member-per-month health-care costs than those with diabetes, depression, asthma, or coronary artery disease. This was largely due to higher costs for medications and psychiatric care (inpatient and outpatient) among those with BD. Only individuals diagnosed with both diabetes and coronary artery disease had higher all-cause health-care costs than those with BD. Sixty-four percent of total costs for the BD group were incurred by a small subgroup (20\%) of patients; who were more likely to be female, have frequent hospital stays, and have a higher number of comorbidities. ${ }^{37}$

In a cohort of community-dwelling dual-eligible Medicare/Medicaid beneficiaries with a mental health disorder in 2005, individuals with a diagnosis of BD had $34 \%$ higher medical care costs, and 59\% higher prescription drug expenditures than those without a diagnosis of $\mathrm{BD}$. 
Table I Direct Health-Care Costs (Annualized, per Person, 2018 USD)

\begin{tabular}{|c|c|c|c|c|c|c|c|c|}
\hline \multirow[t]{2}{*}{ Cohort } & \multirow[t]{2}{*}{ Data Source } & \multirow[t]{2}{*}{ Study } & \multirow{2}{*}{$\begin{array}{l}\text { Study } \\
\text { Period }\end{array}$} & \multicolumn{3}{|c|}{ Services Included } & \multirow[t]{2}{*}{ All-Cause Costs } & \multirow{2}{*}{$\begin{array}{l}\text { Mental Health } \\
\text { Costs }\end{array}$} \\
\hline & & & & $\begin{array}{l}\text { Inpatient, } \\
\text { Outpatient, } \\
\text { Pharmacy }\end{array}$ & $\begin{array}{l}\text { Emergency } \\
\text { Room }\end{array}$ & $\begin{array}{l}\text { Other } \\
\text { Services } †\end{array}$ & & \\
\hline BD-I & $\begin{array}{l}\text { Commercial } \\
\text { claims } \\
\text { Medicaid claims }\end{array}$ & $\begin{array}{l}\text { Bagalman et al, } 2011^{33} * \\
\text { Durden et al, } 2010^{34 *}\end{array}$ & $\begin{array}{l}2004-2007 \\
2004-2006\end{array}$ & - & $\bullet$ & & $\begin{array}{l}\$ 12,913-\$ 19,446 \\
\$ 11,239-\$ 15,699\end{array}$ & $\begin{array}{l}\$ 4521-\$ 9132 \\
\$ 4823-\$ 8299\end{array}$ \\
\hline \multirow[t]{4}{*}{ BD } & $\begin{array}{l}\text { Commercial } \\
\text { claims }\end{array}$ & $\begin{array}{l}\text { Busch et al, } 2013^{44} * * \\
\text { Centorrino et al, } 2009^{12} \\
\text { Guo et al, } 2008^{46} \\
\text { Jing et al, } 2009^{35} \\
\text { Pelletier et al, } 2013^{56} \\
\text { Stensland et al, } 2010^{48} \\
\text { Williams et al, } 2011^{37}\end{array}$ & $\begin{array}{l}1999-2002 \\
2004-2005 \\
1998-2002 \\
2003-2006 \\
2007-2008 \\
1999-2005 \\
2004-2007\end{array}$ & $\begin{array}{l}\bullet \\
\bullet \\
\bullet \\
\bullet \\
\bullet \\
\bullet \\
\bullet \\
\bullet\end{array}$ & • & • & $\begin{array}{l}- \\
\$ 19, \mid 31 \\
\$ 21,707 \\
\$ 37,958-\$ 46,791 \\
\$ 27,665-\$ 29,842 \\
\$ 14,892-\$ 17,568 \\
\$ 21,694\end{array}$ & $\begin{array}{l}\$ 6580 \\
- \\
\$ 7163 \\
\$ 10,545-\$ 21,523 \\
- \\
- \\
-\end{array}$ \\
\hline & MCO claims & $\begin{array}{l}\text { Haskins et al, } 2010^{39} \\
\text { Stensland et al, } 2010^{77} \\
\text { Tohen et al, } 2017^{36}\end{array}$ & $\begin{array}{l}1999-2005 \\
2002-2003 \\
2012-2014\end{array}$ & $\begin{array}{l}\bullet \\
\bullet \\
\bullet\end{array}$ & • & & $\begin{array}{l}- \\
\$ 17,201-\$ 37,489 \\
\$ 11,051-\$ 16,953\end{array}$ & $\begin{array}{l}\$ 6374-\$ 15,189 \\
- \\
\$ 8540-\$ 12,603\end{array}$ \\
\hline & Medicaid claims & 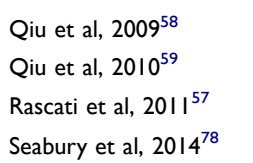 & $\begin{array}{l}2000-2005 \\
2000-2005 \\
2002-2008 \\
2001-2008\end{array}$ & $\begin{array}{l}\bullet \\
\bullet \\
\bullet \\
\bullet\end{array}$ & & • & $\begin{array}{l}\$ 21,563-\$ 25,328 \\
\$ 20,500-\$ 24,049 \\
\$ 25,110 \\
\$ 24,209\end{array}$ & $\begin{array}{l}\$ 6830-\$ 7179 \\
\$ 6915-\$ 9507 \\
\$ 15,036 \\
-\end{array}$ \\
\hline & State agencies & Robertson et al, $2015^{79}$ & 2006-2007 & $\bullet$ & & $\bullet$ & - & $\begin{array}{l}\$ 15,234 \\
\$ 17,753^{*} * *\end{array}$ \\
\hline
\end{tabular}

Notes: *Includes deductibles and co-payments; **limited to those with resource use; ${ }^{* * *}$ Costs over a 2 -year period; - denotes not reported. ${ }^{\dagger}$ Other services include the use of intermediate care or skilled nursing facility, home-based care, ambulance, and laboratory tests.

Abbreviations: BD, bipolar disorder; BD-I, bipolar I disorder; MCO, managed care organization; USD, US dollars.

Among members of this group who used Medicaid-paid community-based long-term care services (eg, in-home services), a diagnosis of $\mathrm{BD}$ was associated with $5 \%$ higher medical care costs, $15 \%$ higher long-term care costs, and 55\% higher prescription drug expenditures than those without a diagnosis of $\mathrm{BD}$. The authors reported a similar pattern for individuals who resided in Medicaidpaid institutional (eg, nursing home) long-term care facilities, noting the increased medication costs relative to those with other mental health diagnoses were expected due to this population's greater reliance on pharmacotherapy and having more comorbid conditions. ${ }^{38}$

\section{Costs Related to Mental Health Care and Psychiatric Hospitalization}

Eleven studies (two for BD-I, nine for BD) evaluated mental health-related costs (Table 1). These studies estimated that annual mental health-related costs totaled between \$4521 and \$9132 PPPY for individuals with BD-I ${ }^{33,34}$ and between $\$ 6374$ and $\$ 21,523$ PPPY for individuals with $\mathrm{BD} .^{35,39}$
Two studies examined the cost of psychiatric hospitalization. The first estimated the cost of a psychiatric hospitalization in patients with BD-I to be $\$ 9544 .{ }^{40}$ This figure is within the range reported by Stensland et al, who reported that the average cost of community hospital-based inpatient psychiatric care for patients with BD was $\$ 1159$ to $\$ 1262$ per day, depending on payer, with an average length of stay between 5.5 days (uninsured) and 9.4 days (Medicare). ${ }^{41}$

\section{Health-Care Resource Utilization}

HCRU was reported in four studies (Table 2); however, no study reported data specific to patients with BD-I. A diagnosis of BD was associated with high use of outpatient, inpatient, emergency, pharmaceutical, medical, and mental health services (eg, psychotherapy, BD-related acute care).

One study found that having a BD diagnosis increased the odds of being a "high-use consumer" of health care by $70 \%$ relative to a diagnosis of depression ("high-use" was defined as using inpatient, mental health ER services, or crisis residential visits three or more times in a fiscal year). ${ }^{42}$ Another study found individuals with a diagnosis of $\mathrm{BD}$ had greater HCRU 
Table 2 Health-Care Utilization (Annualized) in Cohorts with BD

\begin{tabular}{|c|c|c|}
\hline Study & $\begin{array}{l}\text { Study Design } \\
\text { [Sample] } \\
\text { Evaluation Period }\end{array}$ & Brief Methods and Key Findings \\
\hline $\begin{array}{l}\text { Baldessarini } \\
\text { et al, } 2008^{43}\end{array}$ & $\begin{array}{l}\text { Retrospective study } \\
{[\mathrm{N}=7406(55.4 \% \text { BD-I })]} \\
\text { I year }\end{array}$ & $\begin{array}{l}\text { Described annual mean (per person) medical service use in the } 12 \text { months prior to } \\
\text { initial psychotropic prescription for BD in a commercially-insured sample. } \\
\text { - Outpatient care: } 19.6 \text { visits ( } 23 \% \text { BD-related) } \\
\text { - ER use: } 1.3 \text { visits ( } 32 \% \text { BD-related) } \\
\text { - Hospitalizations: } 0.47 \text { episodes ( } 47 \% \text { psychiatric), mean days: } 3.11\end{array}$ \\
\hline $\begin{array}{l}\text { Busch et al, } \\
2013^{44}\end{array}$ & $\begin{array}{l}\text { Retrospective study } \\
{[\mathrm{N}=\text { I I04 (any BD)] }} \\
\text { I year }\end{array}$ & $\begin{array}{l}\text { Described annual mean (per person) mental health/SUD service use among BD patients } \\
\text { in a commercially-insured sample. } \\
\text { - Outpatient care: psychotherapy (6I.6\% use; } 10.8 \text { visits); medication management } \\
\text { ( } 48.4 \% \text { use; } 4.6 \text { visits) } \\
\text { - \% patients with any mental health/SUD hospitalization: } 7.6 \% \text {, mean inpatient days: } \\
\quad 16.1 \% \text { patients with any mental health/SUD prescription: } 89.2 \%\end{array}$ \\
\hline $\begin{array}{l}\text { Centorrino } \\
\text { et al, } 2009^{12}\end{array}$ & $\begin{array}{l}\text { Retrospective study } \\
{[\mathrm{N}=28,53 \text { I (any } \mathrm{BD} \text { ) vs } \mathrm{N}=85,593 \text { (no }} \\
\text { mental health disorder)] } \\
\text { I year }\end{array}$ & $\begin{array}{l}\text { Compared prevalence of metabolic conditions and health care costs between } \\
\text { individuals with } \mathrm{BD} \text { vs age-/sex-matched individuals with no mental health disorder. The } \\
\mathrm{BD} \text { cohort had a higher prevalence of metabolic comorbidities, which contributed to } \\
\text { significantly greater rates of medical service use ( } \mathrm{P}<0.000 \text { I all comparisons). } \\
\text { Annual medical service use (BD vs no mental health disorder): } \\
\text { - Inpatient admission ( } 22.4 \% \text { vs } 5.0 \%) \\
\text { - ER visit ( } 37.0 \% \text { vs } 14.8 \%) \\
\text { - Outpatient visit ( } 99.9 \% \text { vs } 95.0 \%) \\
\text { - Prescription drug use }(97.5 \% \text { vs } 82.0 \%)\end{array}$ \\
\hline $\begin{array}{l}\text { Lindamer } \\
\text { et al, } 2012^{42}\end{array}$ & $\begin{array}{l}\text { Retrospective study } \\
{[\mathrm{N}=1215 \text { (calculated; } 12 \% \text { any } \mathrm{BD} \text { of }} \\
\mathrm{N}=10,128)] \\
4 \text { years }\end{array}$ & $\begin{array}{l}\text { Examined factors associated with high utilization of acute mental health services } \\
\text { (defined as } \geq 3 \text { acute care episodes) from analyses of records from a regional public } \\
\text { mental health services database. } \\
\text { - Across mental health diagnoses in the sample, } 20 \% \text { of enrollees were classified as } \\
\text { high utilizers in one or more years. } \\
\text { - BD and other psychotic disorder diagnoses increased the likelihood of being a high } \\
\text { utilizer by } \sim 70 \% \text { compared to a depression diagnosis (OR I.7I; } p<0.000 \mathrm{I} \text { ). }\end{array}$ \\
\hline
\end{tabular}

Abbreviations: BD, bipolar disorder; BD-I, bipolar I disorder; ER, emergency room; OR, odds ratio; SUD, substance use disorder.

compared to age- and gender-matched individuals with no mental health disorders or psychotropic medication use, with the greatest increases reported for acute care services. The percentage of patients in the BD cohort with an inpatient admission was four times higher $(22.4 \%$ vs $5.0 \%)$ and the percentage of BD patients with ER visits was more than twice as high $(37.0 \%$ vs $14.8 \%)$ than the matched cohort. Increased use of outpatient visits (99.9\% vs $95.0 \%)$ and prescription drugs $(97.5 \%$ vs $82.0 \%)$ was reported for those with BD relative to the matched cohort. ${ }^{12}$ Two other studies providing descriptive data for annual HCRU among commercially insured patients with $\mathrm{BD}^{43,44}$ and are summarized in Table 2.

\section{Drivers of Direct Health-Care Costs}

Eleven studies reported factors that were associated with either increased or decreased direct health-care costs in individuals with BD-I or BD. Factors associated with increased direct health-care costs included having frequent psychiatric interventions (ie, hospitalization, ER visit), the presence of comorbid medical and psychiatric conditions, nonadherence to BD-related medication, approach to pharmacotherapy (eg, use of certain combination treatments), and suboptimal clinical management due to a misdiagnosis of unipolar depression following a BD diagnosis. ${ }^{12,33,34,37,39,45-50}$

\section{Frequent Psychiatric Intervention}

Three studies (two for BD-I, one for BD) examined patients who had "frequent psychiatric intervention" (FPI) over a 12-month period (Year 1), evaluating their health-care costs over the subsequent 12-month period (Year 2), relative to patients without FPI. Two studies defined FPI as $\geq 2$ ER visits or hospitalizations with a principal diagnosis of $\mathrm{BD}$, addition of a new medication to the first observed treatment regimen, or $\geq 50 \%$ increase 
in $\mathrm{BD}$ medication dose, within a 12-month period. ${ }^{33,34}$ The third study utilized a similar definition for FPI but specified a frequency of $\geq 4$ such events within a 12-month period. ${ }^{39}$ FPI was common, with a prevalence of $40 \%$ to $53 \%$ in BD-I cohorts ${ }^{33,34}$ and $52.5 \%$ in a group with BD-I or BD-II. ${ }^{39}$ Compared to those without FPI, individuals who had FPI incurred greater mental health-related and all-cause medical costs in the year following the FPI (Table 3). They also had a 3.7-fold higher risk of subsequent mental health hospitalization and 3.1-fold higher risk of subsequent ER visits in the year following the FPI. ${ }^{34}$

\section{Comorbidities}

Seven studies (two for BD-I, five for BD) reported on the economic burden of comorbidities among individuals with the disorder (Table 4). Across studies, cardiometabolic comorbidities (eg, hyperglycemia or diabetes,

Table 3 Frequent Psychiatric Intervention

\begin{tabular}{|c|c|c|c|}
\hline Study & $\begin{array}{l}\text { Study Design } \\
\text { [Sample] } \\
\text { Evaluation } \\
\text { Period }\end{array}$ & Definition of FPI & Key Findings \\
\hline $\begin{array}{l}\text { Bagalman } \\
\text { et al, } \\
20 \mathrm{II}^{33}\end{array}$ & $\begin{array}{l}\text { Retrospective } \\
\text { study } \\
{[N=|9,| 9 \mid(B D-I)]} \\
\text { I year }\end{array}$ & \multirow[t]{2}{*}{$\begin{array}{l}\text { Having } \geq 2 \text { clinically significant events during the } 12 \text { - } \\
\text { month identification period (Year I) after the first } \\
\text { observed diagnosis of BD-I. A clinically significant } \\
\text { event included ER visits or hospitalizations with a } \\
\text { principal diagnosis of BD (any type), addition of a new } \\
\text { medication to the first observed treatment regimen, } \\
\text { or } \geq 50 \% \text { increase in BD medication dose. }\end{array}$} & $\begin{array}{l}\text { - In Year I, prevalence of FPI was } 40 \% \text {. } \\
\text { - Of patients with FPI in Year I, } 22 \% \text { also had FPI in } \\
\text { Year } 2 \text {. } \\
\text { - BD-I patients with FPI (vs without) in Year I had } \\
\text { greater mental health-related costs ( } \$ 9 \mid 32 \text { vs } \$ 452 \text { I } \\
\text { PPPY) and all-cause costs ( } \$ 19,446 \text { vs } \$ 12,913 \\
\text { PPPY) in Year } 2 \text {. } \\
\text { - Patients with FPI (vs without) in Year I had signifi- } \\
\text { cantly more mental health-related hospitalizations } \\
\text { (I4.6\% vs } 2.8 \% \text { ) in Year } 2 \text { with a longer mean length } \\
\text { of stay ( } 11.7 \text { vs } 8.2 \text { days; all } P<0.00 I \text { ). }\end{array}$ \\
\hline $\begin{array}{l}\text { Durden } \\
\text { et al, } \\
2010^{34}\end{array}$ & $\begin{array}{l}\text { Retrospective } \\
\text { study } \\
{[N=5527(B D-I)]} \\
\text { I year }\end{array}$ & & $\begin{array}{l}\text { - In Year I, prevalence of FPI was } 53 \% \text {. } \\
\text { - Of patients with FPI in Year I, } 29 \% \text { also had FPI in } \\
\text { Year } 2 \text {. } \\
\text { - BD-I patients with FPI (vs without) in Year I had } \\
\text { higher adjusted mental health-related ( } \$ 8299 \text { vs } \\
\$ 4823 \text { PPPY) and all-cause costs }(\$ 15,699 \text { vs } \\
\$ 1 \text { I, } 239 \text { PPPY) in Year } 2 \text {. } \\
\text { - In Year 2, patients with FPI had 3.7-times greater } \\
\text { odds of mental health-related hospitalization and } \\
\text { 3.I-times greater odds of mental health-related ER } \\
\text { visit than patients without FPI. }\end{array}$ \\
\hline $\begin{array}{l}\text { Haskins } \\
\text { et al, } \\
2010^{39}\end{array}$ & $\begin{array}{l}\text { Retrospective } \\
\text { study } \\
\text { [N=632 (BD-I or } \\
\text { BD-II)] } \\
7 \text { years, max }\end{array}$ & $\begin{array}{l}\text { Having } \geq 4 \text { clinically significant events requiring } \\
\text { intervention in any } 12 \text {-month period. A clinically } \\
\text { significant event was defined as a BD-related ER visit, } \\
\text { inpatient psychiatric hospitalization, or a change in } \\
\text { psychotropic medication associated with psychiatric } \\
\text { symptoms. }\end{array}$ & $\begin{array}{l}\text { - In Year I, prevalence of FPI was } 52.5 \% \text {. } \\
\text { BD patients with FPI (vs without) in Year I had } \\
\text { higher mental health-related costs }(\$ 15,189 \text { vs } \\
\$ 6374 \text { PPPY) in Year } 2 \text {. } \\
\text { - Inpatient hospitalization accounted for the greatest } \\
\text { percentage of direct mental health-related costs } \\
\text { ( } 43.7 \% \text { of total direct costs) for patients with FPI in } \\
\text { Year } 2 \text {. } \\
\text { - Mean days hospitalized were greater for the patients } \\
\text { with FPI ( } 5.5 \text { days) compared to those without FPI } \\
\text { ( I.7 days; } p=0.000 \text { I). }\end{array}$ \\
\hline
\end{tabular}

Notes: All three studies identified patients who had FPI over a 12-month period (Year I) and examined health care costs for these patients over the subsequent 12-month period (Year 2) relative to patients without FPI. Costs adjusted to 2018 US dollars.

Abbreviations: BD, bipolar disorder; BD I, bipolar I disorder; BD II, bipolar II disorder; ER, emergency room; FPI, frequent psychiatric interventions; max, maximum; PPPY, per patient per year. 
Table 4 Economic Impact of Comorbidities in Persons with BD

\begin{tabular}{|c|c|c|}
\hline Study & $\begin{array}{l}\text { Study Design } \\
\text { [Sample] } \\
\text { Evaluation Period }\end{array}$ & Key Findings \\
\hline $\begin{array}{l}\text { Bagalman } \\
\text { et al, } 2011^{33}\end{array}$ & $\begin{array}{l}\text { Retrospective study } \\
{[\mathrm{N}=|9,19|(\mathrm{BD}-1)]} \\
\text { I year }\end{array}$ & $\begin{array}{l}\text { - Patients with FPI in Year I incurred significantly increased mental health-related and } \\
\text { all-cause acute medical care costs and outpatient visits in the following year relative to } \\
\text { those without FPI. } \\
\text { - The FPI group had greater comorbidity burden relative to the patients without FPI. } \\
\text { Comorbidities that were significantly higher for the FPI group (vs without FPI) } \\
\text { included mean CCI ( } 0.46 \text { vs } 0.38 \text { ) and a higher prevalence of comorbid depression } \\
\text { ( } 45.2 \% \text { vs } 28.8 \%) \text {, hypertension ( } 39.8 \% \text { vs } 34.6 \%) \text {, anxiety disorder (I7.6\% vs } 9.0 \% \text { ), } \\
\text { substance-abuse disorder ( } 14.3 \% \text { vs } 4.0 \%) \text {, and schizophrenia ( } 9.3 \% \text { vs } 3.6 \%) \text { (all } \\
\text { P<0.00I). }\end{array}$ \\
\hline $\begin{array}{l}\text { Centorrino } \\
\text { et al, } 2009^{12}\end{array}$ & $\begin{array}{l}\text { Retrospective study } \\
{[\mathrm{N}=28,53 \text { | (any BD) vs } \mathrm{N}=85,593 \text { (no }} \\
\text { mental health disorder)] } \\
\text { I year }\end{array}$ & $\begin{array}{l}\text { - Prevalence of metabolic comorbidities was significantly greater for the BD cohort vs } \\
\text { no mental health disorder ( } 37 \% \text { vs } 30 \%, \mathrm{p}<0.000 \mathrm{I}) \text { contributing to direct medical } \\
\text { costs that were four times higher in persons with } B D \text { vs no mental health disorder } \\
(\$ 19,13 \mathrm{I} \text { vs } \$ 4706[\mathrm{PPPY}] \text { ). } \\
\text { - Direct medical and pharmacy costs (PPPY) to treat metabolic conditions were } \\
\text { approximately twice as high for persons with BD vs no mental health disorder } \\
\text { (medical: } \$ 796 \text { vs } \$ 349 \text {; pharmacy: } \$ 856 \text { vs } \$ 45 \mathrm{I} \text { ). }\end{array}$ \\
\hline $\begin{array}{l}\text { Correll et al, } \\
2017^{50}\end{array}$ & $\begin{array}{l}\text { Retrospective study } \\
{[\mathrm{N}=124,803 \text { (any BD)] }} \\
30 \text {-days post-index hospitalization }\end{array}$ & $\begin{array}{l}\text { - Cardiometabolic comorbidity burden was high among hospitalized patients with an } \\
\text { inpatient diagnosis of BD }(60.5 \% \text { had } \geq \mathrm{I} \text { comorbidity and } 33.4 \% \text { had } \geq 2 \\
\text { comorbidities). } \\
\text { - In this inpatient sample, each additional cardiometabolic comorbidity was associated } \\
\text { with: } \\
\text { - Direct costs that were higher by } 12.3 \% \text { (medical), } 26.6 \% \text { (pharmacy), and I3.4\% (total; } \\
\text { all } p<0.000 \mathrm{I}) \text {. } \\
\text { - Significantly higher in-hospital mortality rate, longer hospital stays, and greater like- } \\
\text { lihood of } 30 \text {-day readmission for any cause (all } p<0.00 \mathrm{I}) \text {. }\end{array}$ \\
\hline $\begin{array}{l}\text { Durden et al, } \\
2010^{34}\end{array}$ & $\begin{array}{l}\text { Retrospective study } \\
{[\mathrm{N}=5527(\mathrm{BD}-\mathrm{I})]} \\
\text { I year }\end{array}$ & $\begin{array}{l}\text { - Over a I-year period, higher (vs lower) comorbidity burden in patients with FPI (vs } \\
\text { without FPI) was associated with higher total medical and psychiatric costs, and } \\
\text { higher probability of mental health-related hospitalization and mental health-related } \\
\text { ER visit in a Medicaid sample. } \\
\text { - In the cost analysis, comorbidity factors associated with higher total costs for those } \\
\text { with FPI included having a higher mean } \mathrm{CCl} \text { score and having hypertension or } \\
\text { dyslipidemia. } \\
\text { - Overall, the FPI group had greater comorbidity burden relative to the patients with- } \\
\text { out FPI. Patients with FPI had significantly higher mean } \mathrm{CCl}(0.59 \text { vs } 0.45) \text { and a } \\
\text { significantly higher prevalence of comorbid depression }(4 \mathrm{I} .3 \% \text { vs } 25.0 \%) \text {, hypertension } \\
\text { (39.8\% vs } 33.9 \%) \text {, anxiety disorder }(29.0 \% \text { vs } 14.7 \%) \text {, dyslipidemia }(25.3 \% \text { vs } 22.4 \%) \text {, } \\
\text { and substance use disorder }(22.0 \% \text { vs } 8.0 \%) \text { relative to patients without } \mathrm{FPI}(\mathrm{p}<0.00 \mathrm{I} \\
\text { for all except dyslipidemia }[\mathrm{p}=0.012]) \text {. }\end{array}$ \\
\hline $\begin{array}{l}\text { Guo et al, } \\
2008^{46}\end{array}$ & $\begin{array}{l}\text { Retrospective study } \\
{[N=67,862 \text { (any BD)] }} \\
5 \text { years, max }\end{array}$ & $\begin{array}{l}\text { - Comorbid conditions (psychiatric and medical) accounted for } 67 \% \text { of treatment costs } \\
\text { for patients with } B D \text { in a commercially insured plan. } \\
\text { - The five comorbidities resulting in the highest treatment cost rate ratios }(R R) \text { for } B D \\
\text { patients were personality disorder ( } R R=1.65) \text {; eating disorder }(R R=1.48) \text {; other } \\
\text { mental health disorders }(R R=1.32) \text {; alcohol abuse }(R R=1.30) \text {; and substance use } \\
\text { disorder ( } R R=1.28) \text {. }\end{array}$ \\
\hline
\end{tabular}

(Continued) 
Table 4 (Continued).

\begin{tabular}{|c|c|c|}
\hline Study & $\begin{array}{l}\text { Study Design } \\
\text { [Sample] } \\
\text { Evaluation Period }\end{array}$ & Key Findings \\
\hline $\begin{array}{l}\text { Haskins et al, } \\
2010^{39}\end{array}$ & $\begin{array}{l}\text { Retrospective study } \\
{[\mathrm{N}=632(\mathrm{BD}-\mathrm{I} \text { or BD-II)] }} \\
7 \text { years, max }\end{array}$ & $\begin{array}{l}\text { - Patients with FPI incurred more than twice the mental health-related costs over a I- } \\
\text { year period compared to those without FPI. } \\
\text { - The patients with FPI (vs without) had a significantly higher percentage of psychiatric } \\
\text { comorbidities. The five comorbidities that were more prevalent in patients with FPI } \\
\text { were anxiety disorders ( } 40.4 \% \text { vs } 25.7 \% \text { ), depressive disorders ( } 38.6 \% \text { vs } 23.7 \% \text { ), } \\
\text { personality disorders ( } 31.9 \% \text { vs } 10.0 \%) \text {, substance use disorder diagnosis }(39.8 \% \text { vs } \\
28.0 \%) \text {, and alcohol use disorder ( } 24.4 \% \text { vs } 17.7 \%)(\text { all } p<0.000 \text { I except substance use } \\
\text { disorder }[\mathrm{p}-0.0019] \text { and alcohol use disorder }[\mathrm{p}=0.387]) \text {. }\end{array}$ \\
\hline $\begin{array}{l}\text { Williams et al, } \\
2011^{37}\end{array}$ & $\begin{array}{l}\text { Retrospective study } \\
{[\mathrm{N}=122(\text { any } \mathrm{BD})]} \\
4 \text { years }\end{array}$ & $\begin{array}{l}\text { - In this sample of commercially insured individuals, patients with BD who represented } \\
\text { the top } 20 \% \text { of per person monthly health-care costs averaged more comorbid } \\
\text { conditions (I.I7) vs those who accounted for the bottom } 80 \%(0.42) \text {. } \\
\text { - Diabetes was the predominant comorbidity in the patient group with BD. }\end{array}$ \\
\hline
\end{tabular}

Note: Costs adjusted to 2018 US dollars.

Abbreviations: BD, bipolar disorder; BD-I, bipolar I disorder; CCl, Charlson Comorbidity Index; ER, emergency room; FPI, frequent Psychiatric intervention; HR, hazard ratio; max, maximum; MCO, managed care organization; PPPY, per person per year, RR, rate ratio.

cardiovascular disease, dyslipidemia, hypertension, and obesity) and psychiatric comorbidities (eg, substance/alcohol abuse, anxiety disorder) were associated with higher medical care costs and/or increased HCRU in patients with the disorder.

Patients with FPI incurred significantly higher medical care costs and had significantly greater comorbidity burden compared to those without FPI. ${ }^{33,34,39}$ Comorbidities with significantly higher prevalence rates in patients with FPI included anxiety disorder, substance use disorder, and depressive disorder. Additionally, in the two studies of BD-I populations, patients with FPI had significantly higher comorbidity scores and significantly greater rates of hypertension and dyslipidemia.33,34 In a cost analysis by Durden et al, these three factors were associated with the higher total annual adjusted all-cause medical costs for patients with FPI relative to those without FPI. ${ }^{34}$

Studies of BD in general also reported that comorbidities contribute significantly to the economic burden of BD. Guo et al estimated that $33 \%$ of PPPY direct health-care costs were related to the treatment of $\mathrm{BD}$, while the remaining $67 \%$ were attributable to treatment of psychiatric (eg, substance/ alcohol use disorders, personality disorder) and medical (eg, obesity, diabetes) comorbidities. ${ }^{46}$ Similarly, analyses of health-care claims from an employer-based health plan found that health-care costs associated with BD were driven, in part, by patients' comorbidity burden. ${ }^{37}$
Another two studies reported associations between cardiometabolic comorbidity burden and increased acute care HCRU and costs for BD patients. In an evaluation of administrative hospital data for 30 days post-discharge, $60.5 \%$ of patients with an inpatient diagnosis of BD had at least one cardiometabolic comorbidity, and 33.4\% had two or more. Those with one or more cardiometabolic conditions (vs none) had an increased likelihood of hospital readmission in the 30 days post-discharge, higher costs, longer lengths of stay, and higher in-hospital mortality. ${ }^{50}$ Centorrino et al reported that individuals with BD had significantly more metabolic comorbidities than matched individuals from the general population (prevalence $37 \%$ vs $30 \%, \mathrm{p}<0.0001)$. This was reflected in significantly higher medical service, particularly due to inpatient admissions, ER visits, and prescription costs for these conditions in the BD cohort. ${ }^{12}$

\section{Adherence to BD-Related Medication}

Six studies (one for BD-I, five for BD) reported on economic aspects of adherence to BD-related medications, using various definitions of adherence. ${ }^{40,45,51-54}$ Suboptimal adherence to BD medication was common. In a claims database study, only $35.3 \%$ of individuals with BD were adherent as measured by medication possession ratio (MPR) $\geq 0.80$ over 12 months. ${ }^{53}$ Individuals with lower antipsychotic adherence, as measured by MPR, had higher direct health-care costs in the form of inpatient and outpatient mental healthrelated HCRU and expenditures. ${ }^{40,45,51,52}$ For example, one 
retrospective study reported that improved adherence to SGA therapy (ie, a 1-unit increase in MPR) was associated with lower quarterly mental health-related medical costs of $\$ 192$ to $\$ 686$ per patient. ${ }^{45}$ Additionally, suboptimal adherence to BD-related medications resulted in higher indirect costs in the form of reduced workplace productivity $(\$ 427-\$ 1156$ PPPY $)^{53}$ and reduced functional status, ${ }^{53,54}$ compared to those who maintained higher levels of adherence.

\section{Approach to Pharmacotherapy}

Seven studies evaluated associations between medication regimens and health-care service use and/or costs among individuals with $\mathrm{BD}$, predominately with antipsychotics. $^{46,47,55-59}$ One of them, a longitudinal cohort study, found that more than $8 \%$ of patients with $\mathrm{BD}$ receiving a second-generation antipsychotic (SGA) received combination treatment with more than one SGA concurrently; analyses found no association between disease severity and use of combination SGA treatment. Patients receiving a combination SGA regimen had greater rates of adverse events (eg, dry mouth, tremor, and sedation), nearly two- to three-times greater HCRU for medical and psychiatric services, respectively, and this regimen was associated with slightly worse global functioning relative to those treated with SGA monotherapy. ${ }^{55}$ A second study of Medicaid claims for patients initiated on SGA therapy found only $58 \%$ were prescribed a clinically recommended dose of their index SGA. In this subset, there were no significant differences in annual medical and mental health-related costs across individual SGA treatment groups. $^{57}$ Other studies evaluated use of SGAs as a class compared to use of traditional mood stabilizers or in combination with traditional mood stabilizers 46,59 or examined costs differences for BD patients treated with different SGA agents alone or in combination with a mood stabilizer. ${ }^{47,56,58}$ In general, studies that reported significant cost differences between treatment groups were driven by the risk or use of hospital services during the study period. $46,47,56$

\section{BD Patients with Subsequent Diagnoses of Unipolar Depression}

Two studies estimated the occurrence of "incongruent diagnoses" among patients previously diagnosed with $\mathrm{BD}$, defined as receipt of a diagnosis of unipolar depression 12 months following an initial BD diagnosis $(17.5 \%$ to $27.5 \%$ of $\mathrm{BD}$ patients). ${ }^{48,49}$ Unipolar depression diagnoses were considered "incongruent" as depressive episodes among $\mathrm{BD}$ patients would be expected to be treated as $\mathrm{BD}$. The $\mathrm{BD}$ patients who received a subsequent diagnosis of unipolar depression had significantly higher average annual health-care costs (+\$2676 PPPY), three times more psychiatric hospitalizations, and twice as many psychiatric ER visits than $\mathrm{BD}$ patients without a subsequent unipolar depression diagnosis. ${ }^{48}$ A chart review for a subset of patients with incongruent diagnoses found different providers were documented for the initial $\mathrm{BD}$ diagnosis vs the subsequent unipolar depression diagnosis $76 \%$ of the time, suggesting gaps in continuity of care may have contributed to these patterns of "incongruent diagnoses". 49

\section{Direct Non-Health-Care Costs Criminal Justice System}

There were two studies (both in BD-I populations) that reported incremental costs of $\mathrm{BD}$ to the criminal justice system, such as costs of incarceration, policing, and legal costs. $^{60,61}$ In a patient survey, employees with BD-I were more likely to report having been involved in a crime than co-workers without a diagnosis of BD-I. ${ }^{60}$ The second study examined public expenditures related to criminal justice, medical, mental health, and social welfare services for persons arrested in a large Florida county who had serious mental illnesses (SMIs). This analysis found psychiatric diagnosis influenced total expenditures; individuals with BD-I had the second-highest total quarterly costs (\$2525) behind those with a psychotic disorder (\$4209). ${ }^{61}$

\section{Indirect Costs}

\section{National Burden}

The total annual indirect costs of BD-I in the US was estimated at $\$ 158.5$ billion, constituting $72.3 \%$ of the total economic burden of the disorder. ${ }^{31}$ About half $(50.3 \%)$ of indirect costs were related to unemployment; the rest were attributed to caregiving productivity loss (34.1\%); all-cause premature mortality among individuals with BD-I (8.6\%); productivity loss among individuals with BD-I $(6.4 \%)$; and direct health-care costs for caregivers $(0.6 \%)$. The annual all-cause mortality rate for the BD-I population was found to be 3.4- to 11.4-times higher than for the US general population, depending on age group. Suicide was 10.3- to 16.2-times more common than for the general US population, and was responsible for an estimated $19 \%$ of the costs (measured as 
productivity loss) associated with premature deaths among those with BD-I. These findings were similar to another study that estimated total annual indirect costs for BD-I and BD-II of $\$ 155.2$ billion (79.7\% of the total cost burden). ${ }^{32}$

\section{Workplace Productivity}

Seven studies (three for BD-I, four for BD) evaluated effects on workplace productivity or employment, and all found that the disorder had a negative economic impact for employed individuals and their employers (Table 5).

Individuals with BD or BD-I were more likely to be unemployed, miss work, have reduced work hours due to medical or mental health-related reasons, receive disability payments, or have been fired or laid off compared with those with no mood disorders. ${ }^{60,62}$ Studies of employed persons with $\mathrm{BD}$ reported increased indirect costs due to work absence and disability, ${ }^{53}$ as well as functional deficits that adversely affected work quality, work attendance, and ability to maintain employment. ${ }^{63-65}$ Moreover, an increased number of lifetime mood episodes was associated with higher likelihood of permanent disability and unemployment. ${ }^{64}$

\section{Caregivers and Families}

The economic burden of BD often extends to families and caregivers of these patients. In an analysis of the national burden of BD-I in the US, it was estimated that caregivers' productivity loss and direct health-care costs accounted for more than a third of the total annual indirect costs of the disorder. These estimates were based on assumptions that caregivers devoted an average of almost 29 hours per week to caring for an individual with BD-I and that more than half $(57.6 \%)$ of individuals with BD-I resided with family members. ${ }^{31}$ A second study reported that total annual health-care costs were $239 \%$ higher for families containing a member with BD compared to matched families without a diagnosis of SMI. Specifically, families including a member with BD made more outpatient visits, had more inpatient hospital stays, and filled more prescription medications than the matched families. Notably, most of the total HCRU and costs related to conditions other than BD. The authors suggested that this may be related to the psychological stress of living with and/or caring for a family member with BD. Another possibility for the greater HCRU costs observed is that BD families may have more frequent interactions with the health-care system (on behalf of the member with $\mathrm{BD}$ ), providing them with additional opportunities to discuss and/or pursue help with their own health concerns compared to families that do not include a member with a SMI. ${ }^{66}$

\section{Discussion}

This literature synthesis presents a comprehensive review of contemporary literature describing the direct and indirect costs associated with BD and BD-I in real-world settings in the US, and the drivers of those costs. It builds on the findings of prior reviews describing the disease burden of $\mathrm{BD}$, which were more focused on methodologic differences among published studies that specifically described cost data related to the burden of $\mathrm{BD} .{ }^{6,10}$ This review included a broader collection of research than prior reviews, such as papers describing resource use or changes in work productivity without associated cost estimates, for additional perspective on the economic burden of $\mathrm{BD} / \mathrm{BD}-$ I. Because BD encompasses multiple disease subtypes, this review reflected economic drivers that are applicable to both $\mathrm{BD}$ as a whole as well as the subset of patients who live with BD-I. While previous research identified differences in direct medical costs between BD-I and other BD subtypes, ${ }^{6}$ this review allowed for identification of broader cost outcomes and drivers of these costs among patients with BD-I specifically.

National burden estimates for BD and BD-I in this review show the costs associated with this disorder are substantial. Two studies estimated total annual costs of \$195 billion (BD-I and BD-II) and \$219 billion for BD-I (both 2018 USD), in analyses that assumed a lifetime prevalence of $2.1 \%$ (BD-I and BD-II) and 1.0\% (BD-I) of the adult population, respectively. ${ }^{31,32}$ In contrast, the total annual cost of diagnosed diabetes was estimated at $\$ 333$ billion (2018 USD) for a disease that affects 9.7\% of the adult population. ${ }^{67}$ For both BD and BD-I, the majority of total economic burden ( $72 \%$ to $80 \%$ ) was attributed to indirect costs, such as losses in work productivity (eg, unemployment, absences associated with morbidity) and caregiving. These population-level findings were aligned with other studies in this review that reported reduced work attendance, functioning, and ability to maintain employment for individuals with BD or BD- $\mathrm{I}^{53,60,62,65}$ as well as increased HCRU and worsening health status for family members of affected individuals. ${ }^{31,66,68}$ Given the degree to which indirect costs impact the total costs of BD and BD-I, this topic should remain a research priority.

Thirteen studies in this review reported data specific to BD-I populations, summarizing considerable indirect 
Table 5 Effects of BD on Workplace Productivity and Employment

\begin{tabular}{|c|c|c|}
\hline Study & $\begin{array}{l}\text { Study Design } \\
\text { [Sample] } \\
\text { Evaluation Period }\end{array}$ & Key Findings \\
\hline $\begin{array}{l}\text { Bagalman } \\
\text { et al, } 2010^{53}\end{array}$ & $\begin{array}{l}\text { Retrospective study } \\
{[\mathrm{N}=1258 \text { (any BD)] }} \\
\text { I year }\end{array}$ & $\begin{array}{l}\text { - One-year adherence with BD medication was low }(35.3 \%) \text { as measured by MPR } \geq 0.80 \text {. } \\
\text { - Nonadherent (vs adherent) employees had incrementally higher adjusted indirect costs } \\
\text { (PPPY) during the I-year follow-up period due to absence }(+\$ 1 \mid 56) \text {, short-term disability } \\
(+\$ 427) \text {, and worker's compensation }(+\$ 541) \text {. }\end{array}$ \\
\hline $\begin{array}{l}\text { Cloutier et al, } \\
2018^{31}\end{array}$ & $\begin{array}{l}\text { Prevalence-based cost } \\
\text { analysis } \\
{[N=202,019(B D-I)]} \\
\text { I year }\end{array}$ & $\begin{array}{l}\text { - Of } \$ 158.5 \text { billion in annual national indirect costs for BD-I, } 50.3 \% \text { was related to unemploy- } \\
\text { ment, } 6.4 \% \text { was related to productivity loss for individuals with BD-I, and } 34.1 \% \text { represented } \\
\text { productivity loss for caregivers. }\end{array}$ \\
\hline $\begin{array}{l}\text { McMorris } \\
\text { et al, } 2010^{60}\end{array}$ & $\begin{array}{l}\text { Cross-sectional survey } \\
{[N=219(B D-I) \text { matched and }} \\
N=198 \text { (no BD-I)] } \\
\text { NA }\end{array}$ & $\begin{array}{l}\text { - Employees with BD-I had lower levels of work productivity (overall EWPS* mean score } 37.2 \\
\text { BD-I vs I5.8 no BD-I). } \\
\text { - Employees with BD-I were more likely to miss work, work reduced hours due to medical or } \\
\text { mental health issues, receive disability payments, be involved in a crime, or have been fired or } \\
\text { laid off compared to those without the disorder. }\end{array}$ \\
\hline $\begin{array}{l}\text { O'Donnell } \\
\text { et al, } 2017^{63}\end{array}$ & $\begin{array}{l}\text { Longitudinal study } \\
{[\mathrm{N}=273(63.4 \% \mathrm{BD}-\mathrm{I})]} \\
5 \text { years }\end{array}$ & $\begin{array}{l}\text { - Multilevel modeling demonstrated that persons with BD who had higher levels of depression } \\
\text { and greater cognitive flexibility deficits were more likely to experience poorer work atten- } \\
\text { dance }(p<0.0 \mathrm{I}) \text {, lower quality of work }(p<0.0 \mathrm{I}) \text {, and reduced satisfaction from work } \\
(\mathrm{p}<0.00 \mathrm{I}) \text {. } \\
\text { - Clinical and neurocognitive characteristics of persons with BD were predictive of work } \\
\text { functioning over the } 5 \text {-year study. }\end{array}$ \\
\hline $\begin{array}{l}\text { Peters et al, } \\
2016^{64}\end{array}$ & $\begin{array}{l}\text { Cross-sectional survey } \\
{[N=909(B D-1)]} \\
\text { NA }\end{array}$ & $\begin{array}{l}\text { - Multivariate models showed increases in the total number of lifetime mood episodes were } \\
\text { associated with small, but significantly higher likelihood of permanent disability }(b=0.0 \mathrm{I}) \text { and } \\
\text { unemployment }(b=0.0 \mathrm{I}) \text {. } \\
\text { - Recurrent mood episodes and repeated depressive episodes (vs mania) were a consistent } \\
\text { predictor of functional impairments in patients with BD-I. } \\
\text { - Analyses examining the relative effects by type of episode (manic vs depressive) found } \\
\text { repeated manic episodes were a significant predictor of the likelihood of unemployment } \\
\text { whereas repeated depressive episodes were not. }\end{array}$ \\
\hline $\begin{array}{l}\text { Shippee et al, } \\
2011^{62}\end{array}$ & $\begin{array}{l}\text { Cross-sectional survey } \\
{[N=572(\text { any } B D)]} \\
3 \text { years }\end{array}$ & $\begin{array}{l}\text { - This analysis of MEPS data (2004-2006) reported individuals with BD (vs no mood disorder) } \\
\text { were more likely to report being unemployed, missing work, and having social, cognitive, } \\
\text { physical, and household limitations. }\end{array}$ \\
\hline $\begin{array}{l}\text { Simon et al, } \\
2008^{65}\end{array}$ & $\begin{array}{l}\text { Structured interviews } \\
{[\mathrm{N}=44 \mathrm{I}(\mathrm{BD}-\mathrm{I} \text { or } \mathrm{BD}-\mathrm{II})]} \\
2 \text { years }\end{array}$ & $\begin{array}{l}\text { - In this sample of patients with BD, depression was strongly and consistently associated with } \\
\text { - } \text { - Patients with current depression (vs without) were } 15 \% \text { less likely to be employed (OR 0.84). } \\
\text { - Current MDE was associated with significantly lower probability of full-time employment (OR } \\
0.87 \text { ) }\end{array}$ \\
\hline
\end{tabular}

Notes: *The EWPS is a 25-item instrument measuring absenteeism and presenteeism. Total EWPS scores range from zero (best) to I00 (worst). Costs adjusted to 2018 US dollars.

Abbreviations: BD, bipolar disorders; BD-I, bipolar I disorder; BD-II, bipolar II disorder; EWPS, Endicott Work Productivity Scale; MDE, major depressive episode; MEPS, Medical Expenditure Panel Survey; MPR, medication possession ratio; NA, not applicable; OR, odds ratio; PPPY, per person per year.

and direct medical costs, with many of the cost drivers reported similar to those in studies of BD as a whole. Functional impairments among individuals with BD-I were associated with increased risk of unemployment or becoming disabled. ${ }^{31,60,64}$ This risk was higher in persons who experienced recurrent mood episodes. ${ }^{64}$ High direct medical costs, particularly for acute care, were reported for patients with BD-I specifically. ${ }^{31,33,34,40}$ Among those with greater HCRU, nonadherence to pharmacotherapy and presence of comorbid conditions (eg, substance use disorder, hypertension) contributed to higher cost burden. ${ }^{33,34,40}$ These data did not clarify if the BD-I 
subtype is a more costly form of the disease; thus, additional research into real-world indirect and direct costs associated with the clinical management and treatment of BD-I are needed to help inform key stakeholders and public policy decisions for this population.

Taken together, these observations underscore the need to improve patient outcomes and reduce overall economic burden by implementing strategies of disease and medication management. Treatment guidelines recommend patients receive long-term pharmacotherapy to reduce the recurrence of mood episodes and improve the stability of patients' psychiatric and general health, their general functioning, and quality of life; however, this is a population in which medication adherence is typically poor. ${ }^{22,28,69}$ Most currently prescribed mood stabilizing agents have undesirable side effects (eg, changes in cognitive function, tremor) that are poorly tolerated by patients ${ }^{70,71}$ and also have the potential to induce or exacerbate comorbid conditions that may require intervention. ${ }^{22,28,69}$ Choice of medication for $\mathrm{BD}$ is complex, balancing patient needs, symptoms, and treatment preferences with the risks of available therapies.

Interventions aimed at optimizing care delivery, such as integrated health-care programs combining primary care with specialists (eg, psychiatrists, pharmacists), have promise for improving the clinical management of BD and its comorbidities. $^{72-75}$ These teams work collaboratively to tailor treatment choices to patients' psychiatric and medical care needs and to efficiently intervene to address factors that may be barriers to medication adherence. ${ }^{72,75}$ Collaborative care of this kind has the potential to reduce the need for acute, intensive, or emergency health-care interventions by providing better continuity of care, while simultaneously reducing the indirect costs of $\mathrm{BD}$ and improving patients' lives. ${ }^{75}$

Our review should be considered in context of its limitations. Only studies that were published between 2008 and 2018 were included. Importantly, many of the studies characterized costs and burden using definitions of BD that predate the fifth edition of the Diagnostic and Statistical Manual of Mental Disorders (DSM-5). Because the DSM-5 criteria broaden the definition of $\mathrm{BD},{ }^{76}$ cost estimates reported from studies using earlier DSM criteria may not be representative of contemporary clinical experience. Included studies did not shed light on cost differences between persons with BD-I relative to other BD subtypes; however, results from Cloutier et al's recent analysis of the national burden of BD-I in the US suggest that the cost burden of BD-I is similar to figures reported for $\mathrm{BD}$ generally when costs were adjusted to a common year. ${ }^{31}$ The assessment of methodological characteristics of included cost studies found that most sufficiently reported the components in the quality checklist; however, only 4 studies provided results of sensitivity analyses, which may increase the level of uncertainty around some of these estimates. Categorization of nonmedical costs was inconsistent in the literature and limits comparability; for example, costs of criminal justice involvement were categorized differently across studies where it was included in the analysis. In addition, aggregate cost estimates were bundled in ways that made it challenging to reliably separate component costs. Therefore, the CPI for Medical Care as the standard for converting costs to common-year currency (2018) may not accurately reflect BDrelated non-health-care costs.

Other limitations inherent to the literature summarized included methodological variability in approaches to costing of data sources, selection of cost items and comorbidities, statistical methods used, and patient selection. Similar to prior reviews, ${ }^{6,10}$ which discussed the methodological and quality issues in cost studies of BD in greater detail, this review found that greater transparency and specificity in study methods is needed to improve the comparability of results across studies. Many included studies relied on administrative claims data, thus limiting their analyses to those costs for which a payer is responsible. Other relevant costs, such as out-of-pocket payments or expenses carried by other payers (eg, rehabilitation paid from pension funds), were rarely included. Some studies focused on general cost categories (inpatient or outpatient care), while others also included the services of supporting departments such as ER, laboratory, and social work. Some studies matched their samples according to individuals' age and gender; others used statistical methods to adjust for sociodemographic characteristics. Most studies recruited from special populations (eg, privately insured individuals; recent hospital discharges; employed persons) in which reported costs may not be representative of the general BD population. Some cost studies focused on newly available treatments, which may have resulted in higher reported costs compared to studies that included a broader selection of treatments due to increased pharmacy costs. Additionally, inconsistency in the way that "indirect" costs were defined or apportioned across publications led to heterogeneous definitions of indirect cost categories, resulting in widely differing estimates. This variability in 
costing methodologies and definitions limited comparisons across and between studies. However, this review summarized a broad range of studies to provide a comprehensive picture of the economic burden of BD and BD-I.

\section{Conclusion}

There is clear evidence from the published literature that BD (including BD-I specifically) and its comorbidities exert a large economic burden in the US on patients, caregivers, families, employers, and society. This burden encompasses direct health-care utilization and costs, loss of workplace productivity, caregiving, and other indirect costs. While estimates of indirect costs associated with BD and BD-I are substantial, they are infrequently quantified in the literature and warrant further study. Interventions that target better disease management and medication adherence may reduce the direct and indirect cost burden of BD and BD-I and improve patient outcomes.

\section{Abbreviations}

BD, bipolar disorder; BD-I, bipolar I disorder; BD-II, bipolar II disorder; CPI, Consumer Price Index; DSM, Diagnostic and Statistical Manual of Mental Disorders; FPI, frequent psychiatric intervention; HCRU, health-care resource utilization; MPR, medication possession ratio; NHS EED, National Health Service Economic Evaluation Database; PPPY, per person per year; SGA, second-generation antipsychotic; SMI, serious mental illness; US, United States; USD, United States Dollars.

\section{Acknowledgments}

The authors thank Nancy Neil, PhD (Worldwide Clinical Trials, Inc., USA), who assisted in the planning and conduct of the literature searches and analyses. Medical writing and editorial support for the preparation of the manuscript, under the direction of the authors, was provided by Jo Whelan, MSc (Textpharm Limited, UK) and was funded by Alkermes, Inc.

\section{Author Contributions}

All authors made substantial contributions to conception and design, acquisition of data, or analysis and interpretation of data; took part in drafting the article or revising it critically for important intellectual content; gave final approval of the version to be published; and agree to be accountable for all aspects of the work.

\section{Funding}

Funding for the planning and conduct of the systematic literature review and the preparation of this manuscript was provided by Alkermes, Inc. In May of 2019, data included in this manuscript were presented as a poster at the annual meeting of the International Society for Pharmacoeconomics and Outcomes Research (ISPOR) in New Orleans, Louisiana. The poster's abstract was published in "Abstracts" in Value in Health, Vol 22: https:// doi.org/10.1016/j.jval.2019.04.1065.

\section{Disclosure}

Leona Bessonova, Michael J. Doane, and Amy K. O'Sullivan are employees of Alkermes, Inc. and may own stock/options in the company. Kristine Ogden is an employee of Worldwide Clinical Trials, Inc., which has received consulting fees from Alkermes, Inc. for conducting this study. Mauricio Tohen was an employee of Lilly (1997 to 2008) and has received honoraria from or consulted for Abbott, AstraZeneca, Alkermes, Allergan, Bristol-Myers Squibb, GlaxoSmithKline, Lilly, Johnson \& Johnson, Otsuka, Merck, Gedeon Richter Plc, Sunovion, Forest, Roche, Elan, Lundbeck, Teva, Pamlab, Minerva, Neurocrine, Pfizer, Wyeth and Wiley Publishing. The authors report no other conflicts of interest in this work.

\section{References}

1. American Psychiatric Association. Diagnostic and Statistical Manual of Mental Disorders. 5th ed. Arlington, VA: American Psychiatric Publishing; 2013.

2. Vieta E, Berk M, Schulze TG, et al. Bipolar disorders. Nat Rev Dis Primers. 2018;4(1):18008. doi:10.1038/nrdp.2018.8

3. Merikangas KR, Jin R, He JP, et al. Prevalence and correlates of bipolar spectrum disorder in the world mental health survey initiative. Arch Gen Psychiatry. 2011;68(3):241-251. doi:10.1001/ archgenpsychiatry.2011.12

4. Vigo D, Thornicroft G, Atun R. Estimating the true global burden of mental illness. Lancet Psychiat. 2016;3(2):171-178. doi:10.1016/ S2215-0366(15)00505-2

5. Rosa AR, Reinares M, Michalak EE, et al. Functional impairment and disability across mood states in bipolar disorder. Value Health. 2010;13(8):984-988. doi:10.1111/j.1524-4733.2010.00768.x

6. Jin H, McCrone P. Cost-of-illness studies for bipolar disorder: systematic review of international studies. Pharmacoeconomics. 2015;33 (4):341-353. doi:10.1007/s40273-014-0250-y

7. Moreno C, Hasin DS, Arango C, et al. Depression in bipolar disorder versus major depressive disorder: results from the national epidemiologic survey on alcohol and related conditions. Bipolar Disord. 2012;14(3):271-282. doi:10.1111/j.1399-5618.2012.01009.x

8. Rubio JM, Olfson M, Perez-Fuentes G, Garcia-Toro M, Wang S, Blanco C. Effect of first episode axis I disorders on quality of life. $J$ Nerv Ment Dis. 2014;202(4):271-274. doi:10.1097/NMD.000 0000000000117 
9. Begley CE, Annegers JF, Swann AC, et al. The lifetime cost of bipolar disorder in the US: an estimate for new cases in 1998. Pharmacoeconomics. 2001;19(5 Pt 1):483-495. doi:10.2165/ 00019053-200119050-00004

10. Kleine-Budde K, Touil E, Moock J, Bramesfeld A, Kawohl W, Rossler W. Cost of illness for bipolar disorder: a systematic review of the economic burden. Bipolar Disord. 2014;16(4):337-353. doi:10.1111/bdi.12165

11. Wyatt RJ, Henter I. An economic evaluation of manic-depressive illness-1991. Soc Psychiatry Psychiatr Epidemiol. 1995;30(5):213219. doi:10.1007/BF00789056

12. Centorrino F, Mark TL, Talamo A, Oh K, Chang J. Health and economic burden of metabolic comorbidity among individuals with bipolar disorder. J Clin Psychopharmacol. 2009;29(6):595-600. doi:10.1097/JCP.0b013e3181bef8a6

13. Goldstein BI, Liu SM, Zivkovic N, Schaffer A, Chien LC, Blanco C. The burden of obesity among adults with bipolar disorder in the United States. Bipolar Disord. 2011;13(4):387-395. doi:10.1111/ j.1399-5618.2011.00932.x

14. Kemp DE, Gao K, Chan PK, Ganocy SJ, Findling RL, Calabrese JR. Medical comorbidity in bipolar disorder: relationship between illnesses of the endocrine/metabolic system and treatment outcome. Bipolar Disord. 2010;12(4):404-413. doi:10.1111/j.1399-5618.2010. 00823.x

15. Vancampfort D, Vansteelandt K, Correll CU, et al. Metabolic syndrome and metabolic abnormalities in bipolar disorder: a meta-analysis of prevalence rates and moderators. Am J Psychiatry. 2013;170 (3):265-274. doi:10.1176/appi.ajp.2012.12050620

16. Fajutrao L, Locklear J, Priaulx J, Heyes A. A systematic review of the evidence of the burden of bipolar disorder in Europe. Clin Pract Epidemiol Ment Health. 2009;5(1):3. doi:10.1186/17450179-5-3

17. Blanco C, Compton WM, Saha TD, et al. Epidemiology of DSM-5 bipolar I disorder: results from the national epidemiologic survey on alcohol and related conditions - III. J Psychiatr Res. 2017;84:310317. doi:10.1016/j.jpsychires.2016.10.003

18. Judd LL, Akiskal HS, Schettler PJ, et al. Psychosocial disability in the course of bipolar I and II disorders: a prospective, comparative, longitudinal study. Arch Gen Psychiatry. 2005;62(12):1322-1330. doi:10.1001/archpsyc.62.12.1322

19. Merikangas KR, Akiskal HS, Angst J, et al. Lifetime and 12-month prevalence of bipolar spectrum disorder in the national comorbidity survey replication. Arch Gen Psychiatry. 2007;64(5):543-552. doi:10.1001/archpsyc.64.5.543

20. Westman J, Hallgren J, Wahlbeck K, Erlinge D, Alfredsson L, Osby U. Cardiovascular mortality in bipolar disorder: a population-based cohort study in Sweden. BMJ Open. 2013;3(4):e002373. doi:10.1136/ bmjopen-2012-002373

21. Rhee TG, Olfson M, Nierenberg AA, Wilkinson ST. 20-Year trends in the pharmacologic treatment of bipolar disorder by psychiatrists in outpatient care settings. Am J Psychiatry. 2020;appiajp202019091000.

22. Yatham LN, Kennedy SH, Parikh SV, et al. Canadian network for mood and anxiety treatments (CANMAT) and international society for bipolar disorders (ISBD) 2018 guidelines for the management of patients with bipolar disorder. Bipolar Disord. 2018;20(2):97-170.

23. Ostacher MJ, Tandon R, Suppes T. Florida best practice psychotherapeutic medication guidelines for adults with bipolar disorder: a novel, practical, patient-centered guide for clinicians. $J$ Clin Psychiatry. 2016;77(7):920-926. doi:10.4088/JCP.15cs09841

24. NICE. Bipolar Disorder: Assessment and Management. NICE Clinical Guideline 185. London: National Institute for Health and Care Excellence; 2014.

25. Malhi GS, Bassett D, Boyce P, et al. Royal Australian and New Zealand college of psychiatrists clinical practice guidelines for mood disorders. Aust N Z J Psychiatry. 2015;49(12):1087-1206. doi:10.1177/0004867415617657
26. Grunze H, Vieta E, Goodwin GM, et al. The world federation of societies of biological psychiatry (WFSBP) guidelines for the biological treatment of bipolar disorders: acute and long-term treatment of mixed states in bipolar disorder. World J Biol Psychiatry. 2018;19 (1):2-58. doi:10.1080/15622975.2017.1384850

27. Goodwin GM, Haddad PM, Ferrier IN, et al. Evidence-based guidelines for treating bipolar disorder: revised third edition recommendations from the British association for psychopharmacology. $J$ Psychopharmacol. 2016;30(6):495-553. doi:10.1177/026988111663 6545

28. Fountoulakis KN, Grunze H, Vieta E, et al. The international college of neuro-psychopharmacology (CINP) treatment guidelines for bipolar disorder in adults (CINP-BD-2017), part 3: the clinical guidelines. Int J Neuropsychopharmacol. 2017;20(2):180-195. doi:10.1093/ijnp/ pyw 109

29. Frank RG, Beronio K, Glied SA. Behavioral health parity and the affordable care act. J Soc Work Disabil Rehabil. 2014;13(1-2):31-43. doi:10.1080/1536710X.2013.870512

30. United States Bureau of Labor Statistics. Consumer price index; 2018. Available from: http://www.bls.gov/cpi/. Accessed January 18, 2019.

31. Cloutier M, Greene M, Guerin A, Touya M, Wu E. The economic burden of bipolar I disorder in the United States in 2015. J Affect Disord. 2018;226:45-51. doi:10.1016/j.jad.2017.09.011

32. Dilsaver SC. An estimate of the minimum economic burden of bipolar I and II disorders in the United States: 2009. J Affect Disord. 2011;129(1-3):79-83. doi:10.1016/j.jad.2010.08.030

33. Bagalman E, Muser E, Choi JC, et al. Health care resource utilization and costs in a commercially insured population of patients with bipolar disorder type I and frequent psychiatric interventions. Clin Ther. 2011;33(10):1381-1390.e1384. doi:10.1016/j.clinthera.2011. 09.005

34. Durden E, Bagalman E, Muser E, et al. Characteristics, healthcare utilization and costs of bipolar disorder type I patients with and without frequent psychiatric intervention in a medicaid population. J Med Econ. 2010;13(4):698-704. doi:10.3111/13696998.2010.531828

35. Jing Y, Kim E, You M, Pikalov A, Tran QV. Healthcare costs associated with treatment of bipolar disorder using a mood stabilizer plus adjunctive aripiprazole, quetiapine, risperidone, olanzapine or ziprasidone. J Med Econ. 2009;12(2):104-113. doi:10.3111/ 13696990903044092

36. Tohen M, Ng-Mak D, Rajagopalan K, Halpern R, Chuang CC, Loebel A. Patient characteristics associated with use of lurasidone versus other atypical antipsychotics in patients with bipolar disorder: analysis from a claims database in the United States. Prim Care Companion CNS Disord. 2017;19(3). doi:10.4088/PCC.16m02066

37. Williams MD, Shah ND, Wagie AE, Wood DL, Frye MA. Direct costs of bipolar disorder versus other chronic conditions: an employer-based health plan analysis. Psychiatr Serv. 2011;62 (9):1073-1078. doi:10.1176/ps.62.9.pss6209_1073

38. Lum TY, Parashuram S, Shippee TP, et al. Diagnosed prevalence and health care expenditures of mental health disorders among dual eligible older people. Gerontologist. 2013;53(2):334-344. doi:10.10 93/geront/gns 163

39. Haskins JT, Macfadden W, Turner N, et al. Clinical characteristics and resource utilization of patients with bipolar disorder who have frequent psychiatric interventions. J Med Econ. 2010;13(3):552-558. doi: $10.3111 / 13696998.2010 .511064$

40. Lang K, Korn J, Muser E, Choi JC, Abouzaid S, Menzin J. Predictors of medication nonadherence and hospitalization in medicaid patients with bipolar I disorder given long-acting or oral antipsychotics. J Med Econ. 2011;14(2):217-226. doi:10.3111/ 13696998.2011.562265

41. Stensland M, Watson PR, Grazier KL. An examination of costs, charges, and payments for inpatient psychiatric treatment in community hospitals. Psychiatr Serv. 2012;63(7):666-671. doi:10.1176/appi. ps. 201100402 
42. Lindamer LA, Liu L, Sommerfeld DH, et al. Predisposing, enabling, and need factors associated with high service use in a public mental health system. Adm Policy Ment Health. 2012;39(3):200-209. doi:10.1007/s10488-011-0350-3

43. Baldessarini R, Henk H, Sklar A, Chang J, Leahy L. Psychotropic medications for patients with bipolar disorder in the United States: polytherapy and adherence. Psychiatr Serv. 2008;59(10):1175-1183. doi:10.1176/ps.2008.59.10.1175

44. Busch AB, Yoon F, Barry CL, et al. The effects of mental health parity on spending and utilization for bipolar, major depression, and adjustment disorders. Am J Psychiatry. 2013;170(2):180-187. doi:10.1176/appi.ajp.2012.12030392

45. Gianfrancesco FD, Sajatovic M, Rajagopalan K, Wang RH. Antipsychotic treatment adherence and associated mental health care use among individuals with bipolar disorder. Clin Ther. 2008;30(7):1358-1374. doi:10.1016/S0149-2918(08)80062-8

46. Guo JJ, Keck PE Jr, Li H, Jang R, Kelton CM. Treatment costs and health care utilization for patients with bipolar disorder in a large managed care population. Value Health. 2008;11(3):416-423. doi:10.1111/j.1524-4733.2007.00287.x

47. Kim E, You M, Pikalov A, Van-Tran Q, Jing Y. One-year risk of psychiatric hospitalization and associated treatment costs in bipolar disorder treated with atypical antipsychotics: a retrospective claims database analysis. BMC Psychiatry. 2011;11(1):6. doi:10.1186/1471244X-11-6

48. Stensland MD, Schultz JF, Frytak JR. Depression diagnoses following the identification of bipolar disorder: costly incongruent diagnoses. BMC Psychiatry. 2010;10(1):39. doi:10.1186/1471-244X-1039

49. Stensland MD, Schultz JF, Frytak JR. Diagnosis of unipolar depression following initial identification of bipolar disorder: a common and costly misdiagnosis. J Clin Psychiatry. 2008;69(5):749-758. doi:10.4088/JCP.v69n0508

50. Correll CU, Ng-Mak DS, Stafkey-Mailey D, Farrelly E, Rajagopalan K, Loebel A. Cardiometabolic comorbidities, readmission, and costs in schizophrenia and bipolar disorder: a realworld analysis. Ann Gen Psychiatry. 2017;16(1):9. doi:10.1186/ s12991-017-0133-7

51. Hassan M, Lage MJ. Risk of rehospitalization among bipolar disorder patients who are nonadherent to antipsychotic therapy after hospital discharge. Am J Health Syst Pharm. 2009;66(4):358-365. doi:10. 2146/ajhp080374

52. Lage MJ, Hassan MK. The relationship between antipsychotic medication adherence and patient outcomes among individuals diagnosed with bipolar disorder: a retrospective study. Ann Gen Psychiatry. 2009;8(1):7. doi:10.1186/1744-859X-8-7

53. Bagalman E, Yu-Isenberg KS, Durden E, Crivera C, Dirani R, Bunn WB 3rd. Indirect costs associated with nonadherence to treatment for bipolar disorder. J Occup Environ Med. 2010;52(5):478-485. doi:10. 1097/JOM.0b013e3181db811d

54. Perlis RH, Ostacher MJ, Miklowitz DJ, et al. Clinical features associated with poor pharmacologic adherence in bipolar disorder: results from the STEP-BD study. J Clin Psychiatry. 2010;71(3):296-303. doi:10.4088/JCP.09m05514yel

55. Brooks JO, Goldberg JF, Ketter TA, et al. Safety and tolerability associated with second-generation antipsychotic polytherapy in bipolar disorder: findings from the systematic treatment enhancement program for bipolar disorder. J Clin Psychiatry. 2011;72(2):240247. doi:10.4088/JCP.09m05214yel

56. Pelletier E, Hassan M, Alemayehu B, Smith D, Kim J. Bipolar disorder healthcare costs for quetiapine extended-release versus aripiprazole. Am J Pharm Benefits. 2013;5(3):e73-e79.

57. Rascati KL, Richards KM, Ott CA, et al. Adherence, persistence of use, and costs associated with second-generation antipsychotics for bipolar disorder. Psychiatr Serv. 2011;62(9):1032-1040. doi:10.1176/ ps.62.9.pss6209_1032
58. Qiu Y, Christensen DB, Fu AZ, Liu GG. Cost analysis in a medicaid program for patients with bipolar disorder who initiated atypical antipsychotic monotherapy. Curr Med Res Opin. 2009;25(2):351361. doi: $10.1185 / 03007990802634077$

59. Qiu Y, Fu AZ, Liu GG, Christensen DB. Healthcare costs of atypical antipsychotic use for patients with bipolar disorder in a medicaid programme. Appl Health Econ Health Policy. 2010;8(3):167-177. doi:10.2165/11318830-000000000-00000

60. McMorris BJ, Downs KE, Panish JM, Dirani R. Workplace productivity, employment issues, and resource utilization in patients with bipolar I disorder. J Med Econ. 2010;13(1):23-32. doi:10.3111/ 13696990903475833

61. Petrila J, Andel R, Constantine R, Robst J. Public expenditures related to the criminal justice system and to services for arrestees with a serious mental illness. Psychiatr Serv. 2010;61(5):516-519. doi:10.1176/ps.2010.61.5.516

62. Shippee ND, Shah ND, Williams MD, Moriarty JP, Frye MA, Ziegenfuss JY. Differences in demographic composition and in work, social, and functional limitations among the populations with unipolar depression and bipolar disorder: results from a nationally representative sample. Health Qual Life Outcomes. 2011;9(1):90. doi:10.1186/1477-7525-9-90

63. O'Donnell LA, Deldin PJ, Grogan-Kaylor A, et al. Depression and executive functioning deficits predict poor occupational functioning in a large longitudinal sample with bipolar disorder. $J$ Affect Disord. 2017;215:135-142. doi:10.1016/j.jad.2017.03.015

64. Peters AT, West AE, Eisner L, Baek J, Deckersbach T. The burden of repeated mood episodes in bipolar i disorder: results from the national epidemiological survey on alcohol and related conditions. J Nerv Ment Dis. 2016;204(2):87-94. doi:10.1097/NMD.0000000000000425

65. Simon GE, Ludman EJ, Unutzer J, Operskalski BH, Bauer MS. Severity of mood symptoms and work productivity in people treated for bipolar disorder. Bipolar Disord. 2008;10(6):718-725. doi:10.11 11/j.1399-5618.2008.00581.x

66. Chatterton ML, Ke X, Lewis BE, Rajagopalan K, Lazarus A. Impact of bipolar disorder on the family: utilization and cost of health care resources. $P$ T. 2008;33(1):15-34.

67. American Diabetes A. Economic costs of diabetes in the U.S. in 2017. Diabetes Care. 2018;41(5):917-928. doi:10.2337/dci18-0007

68. Chessick CA, Perlick DA, Miklowitz DJ, et al. Suicidal ideation and depressive symptoms among bipolar patients as predictors of the health and well-being of caregivers. Bipolar Disord. 2009;11 (8):876-884. doi:10.1111/j.1399-5618.2009.00765.x

69. Bobo WV. The diagnosis and management of bipolar I and II disorders: clinical practice update. Mayo Clin Proc. 2017;92(10):15321551. doi:10.1016/j.mayocp.2017.06.022

70. Baldessarini RJ, Perry R, Pike J. Factors associated with treatment nonadherence among US bipolar disorder patients. Hum Psychopharmacol. 2008;23(2):95-105. doi:10.1002/hup.908

71. Mago R, Borra D, Mahajan R. Role of adverse effects in medication nonadherence in bipolar disorder. Harv Rev Psychiatry. 2014;22 (6):363-366. doi:10.1097/HRP.0000000000000017

72. Kern JS, Cerimele JM. Collaborative care for patients with a bipolar disorder: a primary care FQHC-CMHC partnership. Psychiatr Serv. 2019;70(4):353. doi:10.1176/appi.ps.201900019

73. Kilbourne AM, Barbaresso MM, Lai Z, et al. Improving physical health in patients with chronic mental disorders: twelve-month results from a randomized controlled collaborative care trial. $J$ Clin Psychiatry. 2017;78(1):129-137. doi:10.4088/JCP.15m10301

74. Kilbourne AM, Goodrich DE, O'Donnell AN, Miller CJ. Integrating bipolar disorder management in primary care. Curr Psychiatry Rep. 2012;14(6):687-695. doi:10.1007/s11920-012-0325-4

75. Wright WA, Gorman JM, Odorzynski M, Peterson MJ, Clayton C. Integrated pharmacies at community mental health centers: medication adherence and outcomes. J Manag Care Spec Pharm. 2016;22 (11):1330-1336 
76. Angst J. Bipolar disorders in DSM-5: strengths, problems and perspectives. Int J Bipolar Disord. 2013;1(1):12. doi:10.1186/2194-7511-1-12

77. Stensland MD, Zhu B, Ascher-Svanum H, Ball DE. Costs associated with attempted suicide among individuals with bipolar disorder. $J$ Ment Health Policy Econ. 2010;13(2):87-92.

78. Seabury SA, Goldman DP, Kalsekar I, Sheehan JJ, Laubmeier K, Lakdawalla DN. Formulary restrictions on atypical antipsychotics: impact on costs for patients with schizophrenia and bipolar disorder in Medicaid. Am J Manag Care. 2014;20(2):e52-60.
79. Robertson AG, Swanson JW, Lin H, Easter MM, Frisman LK, Swartz MS. Influence of criminal justice involvement and psychiatric diagnoses on treatment costs among adults with serious mental illness. Psychiatr Serv. 2015;66(9):907-909. doi:10.1176/appi.ps.201500134

\section{Publish your work in this journal}

ClinicoEconomics and Outcomes Research is an international, peerreviewed open-access journal focusing on Health Technology Assessment, Pharmacoeconomics and Outcomes Research in the areas of diagnosis, medical devices, and clinical, surgical and pharmacological intervention. The economic impact of health policy and health systems organization also constitute important areas of coverage. The manuscript management system is completely online and includes a very quick and fair peer-review system, which is all easy to use. Visit http://www.dovepress.com/testimonials.php to read real quotes from published authors. 